\title{
Interactive comment on "Hydrological processes and permafrost regulate magnitude, source and chemical characteristics of dissolved organic carbon export in a peatland catchment of northeastern China" by Yuedong Guo et al.
}

Yuedong Guo et al.

guoyuedong@neigae.ac.cn

Received and published: 31 October 2017

The comments from reviewer 2:

Comment 1. I find that there is substantial room for improvement on the writing style. Response: Thanks for the comment! The paper was largely revised according to the comments, and it had been re-edited carefully to make the writing style more clear.

Comment 2 . The data analysis can be improved, particularly with regards to including uncertainty estimates and exploring influences of different seasons/years. Response: 
Thanks for the comment! DOC loads was re-calculated and the data, as well as the uncertainty estimates, in different years and seasons was listed in table 2 (Page 39).

Comment 3. I find that the authors are not sufficiently highlighting what I find to be the more interesting results. Response: Our results have compared with other research in North America in the revised paper, and the reasons leading to the different results have been discussed extensively. (In Section 4, Lines 370-444 in the revised paper).

Interactive

Comment 4. I find that the authors use vague terms throughout the manuscript. For example, the authors talk about "runoff processes" and "hydrological processes" as the main controls on DOC export, but never clearly define what processes in particular they are referring to. For example, in several places I think it could be better to talk about "shifting flow-paths", rather than use the more general term "hydrological processes". Response: Thanks for the comment! The vague terms were replaced by exact expressions such as "shifting flow-paths" in the revised paper.

Comment 5 . The writing style is generally indirect, unnecessarily wordy, and with main points found at the end of paragraphs or sections. Often I found this made it hard to follow the logic of a paragraph until I had arrived at the main point. I recommend writing using an active voice, and to adopt a style where the main point of a section or a paragraph is indicated early rather than at the end (i.e. point first paragraphs). I also found that many sentences can be re-written much shorter without losing the main message. Response: Thanks for the comment! I re-written some paragraph according the comments especially the discussion sections. The main points of the sections were presented in the beginning of the paragraph.

Comment 6. I find that the data analysis and reporting could be improved. Throughout the manuscript I find that the authors are reporting data with too high precision, using too many significant digits. At the same time, none of the estimates e.g. of DOC export, have uncertainty bounds. The methodology for estimating DOC export is never explained. There are many methods for estimating loads, and many of them

Printer-friendly version

Discussion paper 
will also yield uncertainty bounds. I also think there is a missed opportunity in the data analysis, to run an analysis of covariance (ANCOVA) to see if relationships between discharge and the several DOC characteristics (concentration and fluorescence indices) are statistically different for different seasons or years. If the relationship between discharge and DOC characteristics is dependent on e.g. active layer depth (season), that would be really interesting. I think there are some general qualitative comments along these lines, and it would be very good to show this explicitly. Response: Thanks for the comment! First, the DOC loads were re-estimated by a new method according to the suggestion from the first reviewer. In the revised paper, the DOC load was re-calculated by the program LOADEST with the web-based calculation program (https://engineering.purdue.edu/mapsever/ldc/LOADEST, version 2012). The new result will used in the revised paper (In lines 219-232; Line 302). Second, the relationship between discharge and DOC concentrations in each year was plotted in Figure 4 (Page 45 in the revised paper). Third, the analysis about the relationships between discharge and the three indexes was supplied in Table 1 and Table 4 (Page 38 and 41 ). The result shows that the discharge is the sole controlling factor on DOC inter-annual variation, but not the sole factor for the mean DOC concentration. The inter-seasons analysis was not conducted for lacking enough data for each month.

Comment 7. I find that the authors are emphasizing results/conclusions that are already well established, while perhaps missing an opportunity to highlight some of the findings that I consider more novel. The novel finding to me include the fact that these wetlands do not seem to behave as boreal peatlands in Scandinavia or North America, and thus that we could expect a different response to permafrost thaw at the study catchment. In peatland catchments in boreal Scandinavia or North America, we usually observe that DOC concentrations decrease during periods of higher discharge - a dilution effect. At the studied catchment, the authors report the opposite pattern. As such the studied peatland catchment act much more as an upland catchment where shifts in DOC concentrations and its chemical characteristics is controlled by riparian hydrology, and the shifts in flowpaths from organic surface soils during high flow peri-

Printer-friendly version

Discussion paper 
ods and deeper mineral soil flow-paths during low flow periods. This seems to follow from the shallow peat layer at the studied catchment - and the study nicely shows that there are important shifts in DOC characteristics at the interface between the organic and mineral soil layers. With a deeper active layer, which develops earlier in the season, this would mean that we can expect an increased importance of deeper flow-paths through mineral soils - with associated shifts in DOC export. This to me represents a novel finding, and it contrasts very nicely with results from other regions.

Response: Thanks for the comment! The DOC concentrations, loads and the relationship with discharge was extensively compared with other studies in boreal area including North America in the revised paper (In lines 412-420 in the revised paper). The influence of active layer deepening on DOC chemical characteristics was also carried out in the discussion section in the revised paper (Lines 510-537).

L20. Specify whether you mean organic matter degradation or permafrost degradation. Response: "permafrost degradation" was added in the revised paper in lines 20.

L26. Export at $\sim 4.5 \mathrm{~g} \mathrm{C} \mathrm{m-2} \mathrm{yr-1} \mathrm{is} \mathrm{hardly} \mathrm{"strong} \mathrm{potential"} \mathrm{-} \mathrm{it} \mathrm{is} \mathrm{relatively} \mathrm{moderate}$ catchment DOC exports. Response: The DOC loads were re-estimated to be $4.7 \mathrm{~g} \mathrm{C}$ $\mathrm{m}-2 \mathrm{yr}-1$ which is in the lower range of boreal DOC yields (Lines 412-414 in the revised paper).

L49. This sentence: "However, uncertainties remain regarding to main driving factors involved and the fate of DOC due to complex interactions between hydrological and thermal dynamics and bio-chemical drivers." - what is meant by thermal dynamics and bio-chemical drivers in this context? I think this is a good example of where the authors are vague, and where more specific examples would help convey their message better. Response: This part was re-written in the revised paper. (In lines 48-50). The paper has been largely re-edited to avoid vague expressions.

L84. Another example: "However, uncertainties remain in predicting DOC export processes based on changing hydrological processes." - This is vague since I don't know

Printer-friendly version

Discussion paper 
what you refer to when you say "hydrological processes". Response: This sentence was deleted in the revised paper.

L90. DOC export is not only a function of runoff (if that is what is meant by with hydrological regime"). Catchment land-cover, particularly peatland land cover, has repeatedly been shown to influence catchment DOC export. Response: This sentence was deleted in the revised paper, and some conclusions about the influence of flow path on DOC export were supplied in the introduction section (In lines 52-68 in the revised paper).

L97. Replace "can stably" with "preferentially" Response: This sentence was replaced in the revised paper in line74.

L96-101. Long sentence - split into at least 2 sentences. Response: The sentence was split into 2 sentences (Line 74-78).

L143. What are the permafrost conditions in the catchments? Continuous or confined to the peatlands? Response: The permafrost in the catchment is continuous. This information is added in the revise paper in lines 116, 138-139.

L292. How are these values calculated? Arithmetic means based on all sampling occasions? Or is there an adjustment based on the discharge at the time of sampling? Response: The DOC loads were re-estimated by a new method according to the suggestion from the first reviewer. In the revised paper, the DOC load was re-calculated by the program LOADEST with the web-based calculation program (https://engineering.purdue.edu/mapsever/ldc/LOADEST, version 2012).

L293. Always write out units as mg L-1, not mg/L. Response: Thanks for the comment! The errors were all modified in the revised paper.

Printer-friendly version

L296. Use a SI unit to report mass C export, not t. Response: Thanks for the comment! The unit was altered to the unit $\mathrm{Kg}$.

Discussion paper

L297. How was DOC export calculated? There are several methods for estimating 
DOC export, and with many of them you can also estimate your uncertainty. Right now you are stating the DOC export with very high precision and no error estimates. Simple methods are outlined in Walling and Webb (1985 Marine Pollution Bulletin). Response: The DOC loads were re-estimated by a new method according to the suggestion from the first reviewer. The DOC load was re-calculated by the program LOADEST with the web-based calculation program (Lines 219-232 in the revised paper). L297. Remove "Statistically speaking" as it is colloquial. Response: The two words were deleted in the revised paper.

L297-302. Here it would be good if you could say for how long these events lasted. I.e. $85 \%$ of the DOC export occurred during $\mathrm{X} \%$ of the time of the monitoring program. Response: Thank for the comment. However, I think it is more important to tell the influence of large flood on the DOC load. So the daily discharge is a basic standard to judge the "flood". Meanwhile, it is hard to calculate the lasted time of a flood without a minimum standard of a "flood".

L313. These correlations with discharge - were there distinct correlations during each year or during each season? You could carry out an ANCOVA to see whether slopes or intercepts of relationships differed for different periods. Response: ANCOVA analysis on DOC concentrations and spectral indexes was conducted for different years in the revised paper. The results were added in Table 1 and 4 (Page 38, 41) in the revised paper. The discussions were also added in lines 403-410, 544-549 in the revised paper.

L389-392. I don't see how the first and second parts of this sentence are connected. Response: The first sentence was deleted in the revised paper.

L416-425. I find that this discussion on runoff sources and relationship between discharge and DOC concentrations needs to be explicit about what water sources are considered to dominate stream flow during low-flow periods. In boreal catchments Also, this positive relationship between DOC concentration and discharge is opposite what

Printer-friendly version

Discussion paper 
is generally found in boreal peatland catchments in Scandinavia and North America. What is different? Response: The water source during low-flow period was specified in lines 482-503 in the revised paper. However, it is really hard to explain the reason why there is different relationship with that in North America, for there is no enough data or information. I think it will be done when enough field data were listed together (soil features, seasonal discharge pattern, especially landform and peat locations in the catchment).

L452. I do not agree that peatland-derived DOC should be considered "autochtonuous". Usually that term implies DOC derived from aquatic primary production, and is contrasted to "allochtonous" DOC derived from the terrestrial surroundings. Response: The words "autochtonuous" and "allochtonous" were deleted to avoid misunderstanding in the revised paper.

L511-526. This seems to me like one of the most interesting findings of the study, and could be elaborated on more. Response: More discussion about the finding was added in lines 504-537 in the revised paper.

L538. The word "synthetically" is not appropriate - I believe you mean something like "through synthesis". Response: The word "synthetically" was not appropriate and was deleted in the revised paper. The discussion part on the content was largely re-written.

L555. I don't agree that DOC export among ecosystems within a catchment need to be proportional to the soil organic $C$ stock of each ecosystem. There is no data to support this assumption. Response: The assumption was not appropriate and was deleted in the revised paper.

L563. The term "verified NEE" should not be used. Perhaps you can use the term Net Ecosystem Carbon Balance (NECB), but then you also need to take into account methane-C emissions. Response: Thanks for the suggestion. "Net Ecosystem Carbon Balance (NECB)" is very good. The definition was cited in lines 431-438 in the revised paper. And the methane- $C$ emissions has been accounted in the data as shown in line

Printer-friendly version

Discussion paper
Interactive comment 
429.

L579. This conclusion does not take into account shifts in water quality, including DOC concentrations, due to deepened flow-paths following active layer deepening through the mineral soil under the $30-40 \mathrm{~cm}$ organic soil. Response: Thanks for the comments. Theoretically, temperature rise will lead to the deepened flow-paths resulting lower DOC concentrations. However, the expected declining of DOC concentrations would only happen in the low-flow period when only accounting for only a small part of DOC loads for whole year. The annual DOC loads mainly come from the flood periods, and the DOC is mainly come from the upper organic soil. Therefore, the influence of deepened flow-paths on total DOC load should not be decisive when compared to the total stream discharge.

L581. Stating too high precision on projected increases in precipitation. Also, what are the projected changes to evapotranspiration? If ET increases more than precipitation, then we would expected reduced runoff of course. Response: Thanks for the comments. There is really no estimation about the change in evapotranspiration in the region. The emphasis of the study is to make clear the DOC dynamics following the discharge. There is no sufficient data to support my forecast of future DOC loads. Therefore, the third question put forward in the last part of "Introduction" section was deleted in the revised paper.

L616. The definition of NEE only includes the land-atmosphere exchange of CO2 you have further included DOC export in this NEE estimate that you compare DOC export to, which is not correct. Response: Thanks for the comments. In fact, the data of NEE from the Miao (2014) included the contribution both the $\mathrm{CO} 2$ and $\mathrm{CH} 4$. This information was added in the revised paper in lines 429.

Fig7 and 8. I would recommend that you indicate at what depth the soil type changes from peat to mineral. Response: Thanks for the comments. The depth shown by dotted line was added in the two figures (Page 49 and 50). 
Please also note the supplement to this comment:

https://www.hydrol-earth-syst-sci-discuss.net/hess-2017-412/hess-2017-412-AC2-

supplement.zip

Interactive comment on Hydrol. Earth Syst. Sci. Discuss., https://doi.org/10.5194/hess-2017-

Interactive

412, 2017. 